\title{
Development of an intervention to increase sexual health service uptake by young people
}

Newby, K. , Brown, K. E. , Bayley, J. , Caley, M. , Danahey, A. , Hunt, J. and Critchley, G.

Author post-print (accepted) deposited in CURVE January 2016

Original citation \& hyperlink:

Newby, K. , Brown, K. E. , Bayley, J. , Caley, M. , Danahey, A. , Hunt, J. and Critchley, G. (2016) Development of an intervention to increase sexual health service uptake by young people. HEALTH PROMOTION PRACTICE, volume (In Press)

http://hpp.sagepub.com/

Publisher: SAGE Publications

ISSN $\quad 1524-8399$

ESSN $\quad 1552-6372$

Copyright $(\subset$ and Moral Rights are retained by the author(s) and/ or other copyright owners. A copy can be downloaded for personal non-commercial research or study, without prior permission or charge. This item cannot be reproduced or quoted extensively from without first obtaining permission in writing from the copyright holder(s). The content must not be changed in any way or sold commercially in any format or medium without the formal permission of the copyright holders.

This document is the author's post-print version, incorporating any revisions agreed during the peer-review process. Some differences between the published version and this version may remain and you are advised to consult the published version if you wish to cite from it. 
Submission to Health Promotion Practice - January 2016

1 Development of an intervention to increase sexual health service uptake by young

2 people

\section{Abstract}

4 This study aimed to develop and implement an intervention, delivered via a website and web

5 app, to increase the uptake of sexual health services by young people. The intervention was

6 co-designed with a group of ten young people. Intervention Mapping was used to guide

7 development. To identify barriers and facilitators of access to sexual health services, three

8 focus groups with 24 young people aged 13-19 years, and interviews with 12 professionals

9 recruited from across a range of health and social services, were conducted. Data was

10 analysed using Content Analysis. Evidence was supplemented through a literature review.

11 Barriers and facilitators were categorised as theoretical determinants and then suitable

12 Behavior Change Techniques (BCTs) for targeting them selected. Targeted determinants

13 were: attitude, subjective norm, perceived behavioral control and knowledge. Selected BCTs

14 included 'information about others' approval', 'framing/reframing' and 'credible source'.

15 The website/app enable users to search for services, access key information about them,

16 watch videos about what to expect, and have key concerns removed/addressed. This is the

17 first known digital evidence-based intervention to target this behavior described in the

18 literature. A clear and full description of intervention development and content, including of

19 theorised causal pathways, is provided to aid interpretation of future outcome evaluations. 
Submission to Health Promotion Practice - January 2016

\section{Introduction}

In order to effectively manage their sexual health, people must be able to access sexual health services for a range of purposes. These include obtaining contraception, seeking testing and treatment for sexually transmitted infections (STIs), obtaining pre and post abortion support and counselling, and raising concerns such as sexual abuse and sexual exploitation. This important aspect of prevention is recognised in the National Framework for Sexual Health Improvement (Department of Health, 2013), which emphasises the need to build interventions that motivate service access, based on theory and robust evidence. The high and disproportionate burden of STIs amongst 15-24 year olds (Public Health England, 2014a), and the rate of under-18 years conceptions including terminations (Public Health England, 2014b), suggests that young people have the greatest need to access sexual health services. Paradoxically however, this group report an array of barriers to accessing them. These include for example, concerns about confidentiality, anonymity, and stigma, shame, embarrassment, fear of examination, and not knowing what services provide, where they are or how to access and negotiate them (Bender \& Fulbright, 2013; DiCenso et al., 2001; Garside, Ayres, Owen, Pearson, \& Roizen, 2002; Lindberg, Lewis-Spruill, \& Crownover, 2006; Nwokolo, McOwan, Hennebry, Chislett, \& Mandalia, 2002; Stone \& Ingham, 2003; Thomas, Murray, \& Rogstad, 2006; Wilson \& Williams, 2008). This suggests that young people in particular would benefit from interventions which address barriers to accessing sexual health services and support them to attend.

The use of digital media to deliver sexual health interventions to young people is particularly attractive to interventionists. Access to the internet by young people is almost universal with 97\% of households where children live now online (Office for National Statistics, 2015).

Young people are also frequent and confident users of digital technology (Kanuga \& Rosenfeld, 2004). Over $90 \%$ of 13-16 year olds report daily access to the internet within their 
own homes, and 34\% and 71\% of 13-14 and 15-16 year olds respectively report use when 'out and about' (Livingstone, Haddon, Vincent, Mascheroni, \& Ólafsson K., 2014). This indicates that interventions delivered digitally could have good reach and appeal. The ability of users to access content anonymously, repeatedly, and at convenient times, also has clear advantages over other forms of delivery such as face-to-face (Kanuga \& Rosenfeld, 2004; Skinner, Biscope, Poland, \& Goldberg, 2003). Furthermore, digital media interventions are likely to be cost-effective, as once established ongoing costs can be relatively low. Existing reviews on the effectiveness of digital interventions for sexual health also show promise. Recent meta-analyses have demonstrated that computer-based interventions have favourable effects on the mediators of change in sexual behavior and on safer-sex behaviors themselves (Bailey et al., 2012; Noar, Black, \& Pierce, 2009; Noar, Pierce, \& Black, 2010).

This article describes the development and implementation of a behavior change intervention, delivered via a website and web app, to increase the uptake of sexual health services by young people. To date, interventions aiming to increase the uptake of sexual health services by young people have largely been developed for populations within low- to middle-income countries, have rarely targeted or measured psychological antecedents of service use, and are often poorly described (see for example Denno, Chandra-Mouli, \& Osman, 2012; Kesterton \& Cabral, 2010). Furthermore, whilst some have shown promise, it is impossible to disentangle exactly what has worked or why; for this it is necessary both to have detailed descriptions of interventions and to conduct robust evaluations which examine change in the outcome of interest and its theorised behavioural precursors. To the authors' knowledge, this is the first digital theory-based intervention to target the uptake of sexual health services described in the literature. It is also one of few interventions targeting the psychological antecedents of this behaviour to be described in detail. Clear and full descriptions of intervention development and content, including of theorised causal pathways, are 
increasingly called for (S. Michie et al., 2011). Accordingly, the approach taken to development and implementation are described in detail. Furthermore, the causal pathway is made explicit to enable future evaluation findings to be interpreted in light of this. The methods used for co-creation of the intervention with the priority population, for seeking input from key partners, and for working with a multi-disciplinary project team, are also described to assist others embarking on similar projects.

\section{Methods}

The intervention was developed using Intervention Mapping (IM; Bartholomew, Parcel, Kok, Gottlieb, \& Fernandez, 2011). IM is a framework for the development of theory- and evidence-based programs which is consistent with MRC guidance on developing complex interventions (Medical Research Council, 2008). IM requires structured and detailed planning across a series of sequential and iterative steps as follows: 1) Needs assessment, 2) Creating Matrices of Change Objectives, 3) Selecting methods and Practical Strategies, 4) Programme development, 5) Adoption and Implementation, and 6) Evaluation. Selection of methods for each step is determined by the IM framework. A description of the methods used in the development of this intervention is provided below:

\section{Young People's Partnership Board (YPPB) meetings}

The intervention was co-created with a group of ten young people aged 11-16 years whose involvement was facilitated and supported by a sex education consultant (JH). This group was formed from pupils at one secondary school in Warwickshire. On rotation, two members of the YPPB supported by JH, attended monthly project steering group meetings which were held at the school. At the meetings, activities to generate ideas and content for the 
Submission to Health Promotion Practice - January 2016

96

97

98

99

100

101

102

103

104

105

106

107

108

109

110

111

112

113

114

115

116

117

118

119

intervention were discussed and agreed. The YPPB then met weekly to work on these before reporting back. As well as at weekly meetings, the YPPB communicated with each other and members of the steering group via a private Facebook page set up for the project.

\section{Steering group meetings}

This group consisted of two health psychologists (KN, KB), a public health consultant (MC), project manager for Warwickshire County Council's Respect Yourself campaign (AD), and two members of the YPPB on rotation supported by JH. Once the design team was appointed, the design lead (GC) also attended. The monthly steering group meetings were used to make key decisions, ensure the project was progressing in accordance with the timeline, and to set, review and discuss research activities.

\section{Focus groups with young people}

Three focus groups were run with young people attending youth groups in Coventry and Warwickshire. These were facilitated by two research assistants with several years experience of interviewing young people on sexual health issues. A total of 11 males and 13 females aged 13-19 years old participated. Twenty of the young people described themselves as White, three as Asian, and one as Mixed Ethnicity. The number of participants was determined by the project's budget and resource constraints rather than by the achievement of saturation. The sample included children in full-time education as well as those Not in Employment Education or Training (NEET). A number of Looked After Children (LAC) were included. Institutional ethics approval was sought for their participation. All participants provided informed consent. The groups were asked about perceived barriers and facilitators to using sexual health services. This contributed evidence to the needs assessment (step 1 see below). Discussions were audio recorded and transcribed verbatim. A deductive form of Content Analysis (Mayring, 2000) was used to code elicited barriers and facilitators as 
Submission to Health Promotion Practice - January 2016

enabling, predisposing, or reinforcing factors. The focus groups were also used to find out where young people currently accessed information on sexual health services, and to gather their thoughts on important aspects of intervention delivery. This information was used during step three (see below).

\section{Consultation with key professionals}

Interviews with 12 professionals from a variety of services were conducted including:

Warwickshire Healthy Schools, Democracy Project (youth work in Coventry City Council), Youth Offending Service, Connexions service at Henley College (offering advice on employment, training and education), and Stratford Area Youth Involvement team. The purpose of these interviews was to ascertain the opinions of those who worked closely with young people as to what the content of the intervention should be (contributing to step 3) and how it could be best implemented and promoted (contributing to step 5). The interview schedule was developed by $\mathrm{KN}$ and $\mathrm{KB}$ with input from other steering group members. Interviews were conducted by two research assistants experienced in qualitative research and lasted approximately 20-30 minutes. They took place within the settings from which the professionals were recruited. Once again, the number of interviews was determined by the project's budget and resource constraints rather than by the achievement of saturation.

\section{Literature review}

A review of the published scientific literature was conducted to add to evidence about barriers and facilitators to accessing sexual health services by young people. A search strategy was devised using key words and subject headings. The bibliographic database PsychInfo was searched with date of publication limited to between January 2000 and January 2012, identifying 110 possible articles. The titles and abstracts of these articles were assessed for relevance. The reference list of a key paper was also searched. From both 
Submission to Health Promotion Practice - January 2016

processes, a total of 15 relevant papers were identified. This evidence contributed to the needs assessment (step 1).

All of the above methods were used within the six key IM steps, the outcome of each step being built on within each consecutive step. Table I presents the purpose and outcome of each step and the methods used to achieve these.

\section{Results}

\section{Step 1: Needs Assessment}

The priority population for the intervention was young people aged 13-19 years of age. This age group was selected because evidence indicates that teenagers perceive many barriers to accessing sexual health services (see Introduction), and also for pragmatic reasons - the intervention was to be embedded within an existing website (www.respectyourself.info) aimed at this age group.

The needs assessment used the methods described in Table I. Predisposing, reinforcing, and enabling factors identified through the literature review were added to and refined through evidence from focus groups with young people. The resulting list of factors is presented in the supplementary material (S1). These factors were categorised by health psychologists (KN, KB and JB) into broader theoretical determinants. Evidence on the importance of these determinants, in terms of association with the target behavior, and changeability, in terms of the ability of a (digital) intervention to change these, was discussed. It was agreed that the selected determinants met both of these criteria. The final, selected determinants, and examples of the factors on which they are based, is presented in Table II.

Insert tables I and II about here 
Submission to Health Promotion Practice - January 2016

167

168

169

170

171

172

173

174

175

176

177

178

179

180

\section{Step 2: Creating Matrices of Change Objectives}

The program goal (aim) of this intervention was to increase the uptake of sexual health services by young people. This goal was broken down into five performance objectives, specifying what is required of intervention participants to achieve this goal, as follows: (a) Young people to be aware of the full range of sexual health services and what they provide, (b) Young people to know when they can/should access sexual health services, (c) Young people to know what to expect when visiting sexual health services, (d) Young people to know how to access sexual health services, (e) Young people to be able to communicate effectively with on-site professionals. A matrix was developed by combining these performance objectives and associated determinants to create change objectives (positive statements about what needs to happen in order for the performance objectives to be achieved). Performance and change objectives were discussed, refined and approved by the steering group, including the YPPB. Table III displays a portion of the final matrix, produced as a result of this process (see supplementary material S2 for the full matrix).

Insert table III about here

Prior to selecting methods and practical strategies, Behavior Change Techniques (BCTs) suitable for targeting the selected determinants were identified. This was achieved using Michie and colleagues' Behavior Change Wheel guidance (S. Michie, van Stralen, \& West, 2011). The most appropriate BCTs for each determinant were chosen, excluding those which were either unfeasible given the digital mode of delivery or irrelevant to the target behavior. Table S3 in the supplementary material shows the candidate BCTs and how these were linked to the targeted determinants (identified during step1) in accordance with the guidance. 
Submission to Health Promotion Practice - January 2016

190 Based on the matrix and the list of BCTs, ideas for the look, feel and functionality of the app were developed by the steering group and the YPPB. These ideas were fed into the technical specification, along with views from young people and professionals captured during the needs assessment. The opportunity to build the website/app was advertised. The technical specification formed part of an information pack which was given to interested parties. Two companies applied and were asked to pitch their ideas to the steering group and the YPPB.

Diva Creative was chosen. Over a period of three months, the steering group, this design agency and YPPB worked together to develop practical strategies (what users of the intervention would see and do) to deliver the BCTs. This was a creative and iterative process. All ideas were judged according to their feasibility (ability to be delivered digitally and cost) and ability to effectively deliver the relevant BCTs. Also of crucial importance was their ability to engage the priority population. The YPPB suggested many of the ideas themselves, which developed out of their weekly meetings, and the group also discussed these ideas with their wider network of friends to gain further feedback. The steering group and YPPB made the final decision about which practical strategies should be used based on the above criteria.

Program development largely went hand-in-hand with development of ideas for practical strategies. The YPPB produced a 'young person's specification' for the design team which contained information on the type of content, functions and look that the website/app should have. They asked for example, for a dictionary of sexual health terms, a guide to sexual anatomy, a frequently asked questions page, and for the use of videos and fun content. Ideas were worked up into prototypes by the design team and regularly posted on the Facebook project page for the steering group and YPPB to comment on and then revised accordingly. For example, ideas for website branding such as potential logos and colour schemes were presented which the YPPB commented and voted on. The YPPB produced a substantial 
Submission to Health Promotion Practice - January 2016

215

216

217

218

219

220

221

222

223

224

225

226

227

228

229

230

231

232

233

234

235

236

237

238

proportion of the content. For example, supported by $\mathrm{JH}$, they visited a number of sexual health services to be listed on the website/app and took photos of the entrance, reception area, and consultation rooms. These were to be posted on the website/app alongside each of the relevant services. They also made videos of key members of staff on issues of concern to young people regarding access to services e.g. confidentiality. Throughout the program development phase, and prior to final sign-off, the matrix was revisited to ensure that all change objectives had been targeted. No formal usability testing was conducted although the design agency tested the website for general content flow and navigation and to ensure that it was compatible with the most popular internet browsers. A description of intervention components and the change objectives they addressed is provided in supplementary material S4.

The final intervention can be viewed on the website $\underline{w w w . r e s p e c t y o u r s e l f . i n f o}$ and is contained within the 'services' drop-down. The app is accessed via www.respectyourself.info/mobile. This is a 'web app' which differs from more traditional apps in that it is not downloaded onto the users' device. Instead it is akin to a website but content is automatically adapted so that it appears correctly on whichever device is being used to view it. Screenshots of the website/app are presented in supplementary material S5.

Step 5: Adoption and Implementation

Successful adoption and implementation were recognised as dependent on having a successful marketing strategy in place, and endorsements from users and service providers. Launch of the website and app was carefully planned by the Respect Yourself team, with input from Warwickshire Youth Council. The views of professionals gathered through earlier interviews fed into this. Promotional material was identified and developed including posters, cards, badges, stickers for back of toilet doors, and wobble cards to display on counter-tops in 
Submission to Health Promotion Practice - January 2016

239

240

241

242

243

244

245

246

247

248

249

250

251

252

253

254

255

256

257

258

259

260

261

services (see figure 1). These materials utilised QR codes to allow rapid access to the website and app. The official launch took place in autumn 2012. Promotional materials were sent to all service providers in Coventry and Warwickshire and a number of schools and colleges, and stands promoting the website/app were present at local college and university fresher's events. Professionals were encouraged to promote the website/app and users were encouraged to return to the website/app after visiting services to provide ratings and feedback. A press release was also made resulting in local and national media attention.

Insert figure 1 about here

Step 6: Evaluation

A pilot study has been conducted which provides initial evidence regarding the efficacy of the intervention. Outcome measures used include self-reported and objective service access, and beliefs about services and service access identified through the needs analysis. Details on this pilot study and the findings are reported elsewhere [paper submitted to Health Education Research].

\section{Discussion}

This paper describes the development of a digitally delivered theory-and evidence-based intervention to increase the uptake of sexual health services by young people. The underpinning work has added to the body of knowledge about the main barriers to accessing sexual health services perceived and experienced by young people, identified through evidence synthesis and primary research. These barriers include knowing where services are, what they provide, and what questions and procedures to expect, and also concerns about 
Submission to Health Promotion Practice - January 2016

confidentiality and not having the confidence to communicate needs. The intervention is embedded within a website and web app delivering information, advice and support on sex and relationship issues. It was developed predominantly using Intervention Mapping (Bartholomew et al., 2011), although elements of the Behavior Change Wheel (S. Michie, van Stralen, \& West, 2011) were also used to enable selection of suitable Behavior Change Techniques (BCTs) to target the theoretical determinants.

The intervention encompasses a 'service finder' which enables users to identify services by geographical location and find out key information such as opening times and how to get there. For some services there are photographs of buildings' exterior and interior to assist users in identifying the building on arrival and to help prepare them for their visit. Users can also rate and leave comments on the services, a function which intends to inform other potential users and drive up standards. The intervention also includes a 'what to expect' section containing a number of videos which aim to help prepare users, provide reassurance, and demonstrate that professionals are welcoming and supportive of young people accessing services. There is a 'last minute wobbles' feature which addresses common worries that young people have about visiting sexual health services. It gives advice and strategies to help overcome these worries such as mentally rehearsing a visit. Finally there are 'request slips' which young people can print off or display on their device which inform reception staff within services of the reason for their visit.

There are a number of strengths to this work. With the aid of supplementary material accompanying this paper, readers are provided with a full and detailed description of the process of developing this intervention. Using the tables it is possible to trace the casual path from strategies used to deliver the intervention, right back to barriers to service access identified from the evidence base. In this sense it is clear that the intervention is 'evidencebased' and not 'evidence-inspired', a criticism of many previous behavior change 
Submission to Health Promotion Practice - January 2016

interventions (S. Michie \& Abraham, 2004). The translation of evidence into theory is a further strength. This enables standardised measures of the selected theoretical determinants to be used for evaluation purposes, and for future evaluation to add to the body of knowledge about important theoretical predictors of sexual health behavior. A particular strength was the model for working with the Young People's Partnership Board (YPPB) which enabled codesign. Those on the YPPB reported feeling genuinely involved and listened to, and there has been a positive legacy of their contribution, with many continuing to work together as a group on other sexual health projects for Warwickshire County Council. Involvement of the young people heavily in the design has hopefully meant that the end-product, as well as being theoretically sound, is appealing to young people. A final strength of this work was the high priority placed on achieving successful adoption and implementation. A detailed and adequately funded marketing plan was developed, and consequently high quality promotional materials produced and disseminated widely.

Whilst working in a multi-disciplinary group was a positive aspect of the project, it did present challenges. This group had not worked together before, or used this model of codesign, and many individuals had not had experience of working with some or all of the different types of professionals. Additional time was therefore required to come to understand each other's' expertise, and ways of working, and to derive a shared language. A great deal of learning was gained and will be carried forward to future projects, an example being the point at which to involve the design team. On this project, work went into developing ideas for practical strategies to deliver the BCTs via the website/app before the design team became involved. Much of this then became redundant because this content was judged to be too text heavy which would have created a poor user experience. This project highlighted the importance of involving the design team before substantial time is spent on creating content, ideally just after identifying the BCTs. 
Submission to Health Promotion Practice - January 2016

312 Practical strategies employed by the intervention were not piloted prior to launch of the

313 website and web app. This can be a useful stage at which to examine the efficacy of

314 strategies, and their underlying BCTs in isolation and in combination, to see which are

315 working well, and which should be discarded, revised or replaced (Collins, Murphy, Nair, \&

316 Strecher, 2005). This process can increase the optimization and therefore the potency of the

317 intervention leading to larger effect sizes and therefore improved statistical power for

318 detecting an effect during a later trial (Collins et al., 2005). Unfortunately project time and

319 budget restraints prevented this optimisation phase.

Through this article, the authors have aimed to provide a clear description of the process of developing a behavior change intervention and of its content. Intervention Mapping (Bartholomew et al., 2011) proved to be a useful framework enabling systematic development of an intervention grounded in the needs of the priority population. The least satisfactory step is the point at which 'theoretical methods' are to be selected. We preferred instead to select these using guidance from the Behavior Change Wheel (S. Michie et al., 2011), as this enabled categorisation of these methods as BCTs from a taxonomy developed by a number of experts using a consensus process (S. Michie et al., 2013). Mixing these two frameworks worked well, however we still found the method for identifying BCTs to target specific determinants convoluted and prone to error due to the necessity to link first through intervention functions. This is however the best method currently available for doing this and having health psychologists on the team enabled sensible decisions to be made using their knowledge of behavior change theory.

This work has summarised evidence about the barriers young people face when targeting sexual health services, and has aimed through the intervention to either remove these or support young people to overcome them. Whilst ensuring a sound theoretical basis to the intervention, co-design with the priority population has increased the potential for it to be 
Submission to Health Promotion Practice - January 2016

337

engaging and therefore used. The multi-disciplinary approach provided a strong, stimulating

338 and creative research environment. Development alongside public health practitioners from

339 Warwickshire County Council ensured that the resulting website and web app would be

340 implemented at project-end. Both of these platforms have received consistently high hits

341 since their launch suggesting that the content is indeed appealing to users. 
Submission to Health Promotion Practice - January 2016

342

343

344

345

346

347

348

349

350

351

352

353

354

355

356

357

358

359

360

361

\section{References}

Bailey, J. V., Murray, E., Rait, G., Mercer, C. H., Morris, R. W., Peacock, R., . . Nazareth, I. (2012). Computer-based interventions for sexual health promotion: Systematic review and meta-analyses. International Journal of STD \& AIDS, 23(6), 408-413. doi:10.1258/ijsa.2011.011221

Bartholomew, L. K., Parcel, G. S., Kok, G., Gottlieb, N. H., \& Fernandez, M. E. (2011). Planning health promotion programs: An intervention mapping approach (3rd ed.). San Francisco: Jossey-Bass.

Bender, S. S., \& Fulbright, Y. K. (2013). Content analysis: A review of perceived barriers to sexual and reproductive health services by young people. The European Journal of Contraception \& Reproductive Health Care: The Official Journal of the European Society of Contraception, 18(3), 159-167. doi:10.3109/13625187.2013.776672

Collins, L. M., Murphy, S. A., Nair, V. N., \& Strecher, V. J. (2005). A strategy for optimizing and evaluating behavioral interventions. Annals of Behavioral Medicine, 30(1), 65-73. doi:10.1207/s15324796abm3001_8

Denno, D. M., Chandra-Mouli, V., \& Osman, M. (2012). Reaching youth with out-of-facility HIV and reproductive health services: A systematic review. Journal of Adolescent Health, 51(2), 106-121. doi:10.1016/j.jadohealth.2012.01.004

Department of Health. (2013). A framework for sexual health improvement in England. ( No. 2013). 
Submission to Health Promotion Practice - January 2016

362

363

364

365

366

367

368

369

370

371

372

373

374

375

376

377

378

379

380

381

DiCenso, A., Borthwick, V. W., Busca, C. A., Creatura, C., Holmes, J. A., Kalagian, W. F., \& Partington, B. M. (2001). Completing the picture: Adolescents talk about what's missing in sexual health services. Canadian Journal of Public Health, 92(1), 35-38.

Garside, R., Ayres, R., Owen, M., Pearson, V. A. H., \& Roizen, J. (2002). Anonymity and confidentiality: Rural teenagers' concerns when accessing sexual health services. The Journal of Family Planning and Reproductive Health Care, 28(1), 23-26.

Kanuga, M., \& Rosenfeld, W. D. (2004). Adolescent sexuality and the internet: The good, the bad, and the URL. Journal of Pediatric and Adolescent Gynecology, 17(2), 117-124.

Kesterton, A. J., \& Cabral, d. M. (2010). Generating demand and community support for sexual and reproductive health services for young people: A review of the literature and programs. Reproductive Health, 7, 25.

Lindberg, C., Lewis-Spruill, C., \& Crownover, R. (2006). Barriers to sexual and reproductive health care: Urban male adolescents speak out. Issues in Comprehensive Pediatric Nursing, 29(2), 73-88.

Livingstone, S., Haddon, L., Vincent, J., Mascheroni, G., \& Ólafsson K. (2014). Net children go mobile: The UK report. London: London School of Economics and Political Science.

Mayring, P. (2000). Qualitative content analysis. Forum: Qualitative Social Research [onLine Journal], 1(2)

Medical Research Council. (2008). Developing and evaluating complex interventions: New guidance. MRC. 
Submission to Health Promotion Practice - January 2016

382

383

384

385

386

387

388

389

390

391

392

393

394

395

396

397

398

399

400

401

Michie, S., van Stralen, M. M., \& West, R. (2011). The behaviour change wheel: A new method for characterising and designing behaviour change interventions. Implementation Science, 6 (42).

Michie, S., \& Abraham, C. (2004). Interventions to change health behaviours: Evidencebased or evidence-inspired? Psychology \& Health, 19(1), 29-49.

Michie, S., Abraham, C., Eccles, M. P., Francis, J. J., Hardeman, W., \& Johnston, M. (2011). Strengthening evaluation and implementation by specifying components of behaviour change interventions: A study protocol. Implementation Science: IS, 6, 10-10. doi:10.1186/1748-5908-6-10

Michie, S., Richardson, M., Johnston, M., Abraham, C., Francis, J., Hardeman, W., .. . Wood, C. E. (2013). The behavior change technique taxonomy ( v1) of 93 hierarchically clustered techniques: Building an international consensus for the reporting of behavior change interventions. Annals of Behavioral Medicine, 46(1), 81. doi:10.1007/s12160013-9486-6

Michie, S., van Stralen, M.,M., \& West, R. (2011). The behaviour change wheel: A new method for characterising and designing behaviour change interventions. Implementation Science, 6, 42-42.

Noar, S. M., Black, H. G., \& Pierce, L. B. (2009). Efficacy of computer technology-based HIV prevention interventions: A meta-analysis. AIDS, 23(1), 107-115. doi:10.1097/QAD.0b013e32831c5500 
Submission to Health Promotion Practice - January 2016

402

403

404

405

406

407

408

409

410

411

412

413

414

415

416

417

418

419

420

421

Noar, S. M., Pierce, L. B., \& Black, H. G. (2010). Can computer-mediated interventions change theoretical mediators of safer sex? A meta-analysis. Human Communication Research, 36(3), 261-297. doi:10.1111/j.1468-2958.2010.01376.x

Nwokolo, N., McOwan, A., Hennebry, G., Chislett, L., \& Mandalia, S. (2002). Young people's views on provision of sexual health services. Sexually Transmitted Infections, $78(5), 342-345$.

Office for National Statistics. (2015). Internet access: Households and individuals.

Public Health England. (2014a). Table 3: Selected STI diagnoses and rates by gender, sexual risk and age group, 2009 to 2013. ( No. 2014).

Public Health England. (2014b). Sexual and reproductive health profiles: County and UAs in England. ( No. 2014).

Skinner, H., Biscope, S., Poland, B., \& Goldberg, E. (2003). How adolescents use technology for health information: Implications for health professionals from focus group studies. Journal of Medical Internet Research, 5(4), e32-e32.

Stone, N., \& Ingham, R. (2003). When and why do young people in the united kingdom first use sexual health services? Perspectives on Sexual and Reproductive Health, 35(3), 114120.

Thomas, N., Murray, E., \& Rogstad, K. E. (2006). Confidentiality is essential if young people are to access sexual health services. International Journal of STD \& AIDS, 17(8), 525529. 
Submission to Health Promotion Practice - January 2016

422 Wilson, A., \& Williams, R. (2008). Sexual health services: What do young people want? 423 Ambulatory Child Health, 6(4), 253. 
Table I Protocol based on Intervention Mapping procedure used for development of the program

\begin{tabular}{cccc}
\hline IM step & Purpose & Outcome & Methods employed \\
& To identify what the program & Facilitating, reinforcing and & $\bullet$ Focus groups with young \\
\hline should address & enabling factors related to the & people \\
& underlying problem & $\bullet$ Literature review \\
& & workshops $1 \& 2$ \\
& & $\bullet$ YPPB meetings \\
\hline
\end{tabular}


To clarify the program goal and

performance objectives and to

Program goal and performance

objectives and matrices of

identify the immediate change change objectives

objectives that need to be

achieved in order to realise the

program goal
- Intervention mapping

workshop 3

- YPPB meetings

- Steering group meetings 


IM step Purpose

\begin{tabular}{llll}
\hline 3. Selecting methods (Behavior & To identify Behavior Change & Documentation of BCTs and & $\bullet$ Consultation with \\
Change Techniques) and & Techniques (BCTs) and & strategies linked to change & professionals \\
strategies & strategies linked to change & objectives & programs \\
& objectives, that are most likely & & $\bullet$ YPPB meetings \\
& to bring about the desired & Steering group meetings \\
& behavioral change via the & & $\bullet$ YPPB meetings \\
& identified determinants & & $\bullet$ Steering group meetings \\
\hline 4. Program development & To develop and finalise the & The final program & \\
\hline
\end{tabular}




\begin{tabular}{|c|c|c|c|}
\hline IM step & Purpose & Outcome & Methods employed \\
\hline $\begin{array}{l}\text { 5. Adoption and } \\
\text { implementation }\end{array}$ & $\begin{array}{l}\text { To identify threats to program } \\
\text { uptake and sustainability and } \\
\text { strategies to target these }\end{array}$ & $\begin{array}{l}\text { An adoption and } \\
\text { implementation plan to inform } \\
\text { program roll-out }\end{array}$ & $\begin{array}{l}\text { - Consultation with } \\
\text { professionals } \\
\text { - YPPB meetings } \\
\text { - Steering group meetings }\end{array}$ \\
\hline 6. Evaluation & $\begin{array}{l}\text { To develop and employ } \\
\text { measures for process and } \\
\text { outcome evaluation }\end{array}$ & $\begin{array}{l}\text { Findings of process and } \\
\text { outcome evaluation that can be } \\
\text { used to further refine and } \\
\text { develop the intervention }\end{array}$ & $\begin{array}{l}\text { [details provided in paper } \\
\text { under review elsewhere] }\end{array}$ \\
\hline
\end{tabular}


Table II Examples of predisposing, reinforcing and enabling factors identified through the needs assessment and their categorisation as theoretical determinants

Predisposing, Reinforcing and Enabling factors

Determinants

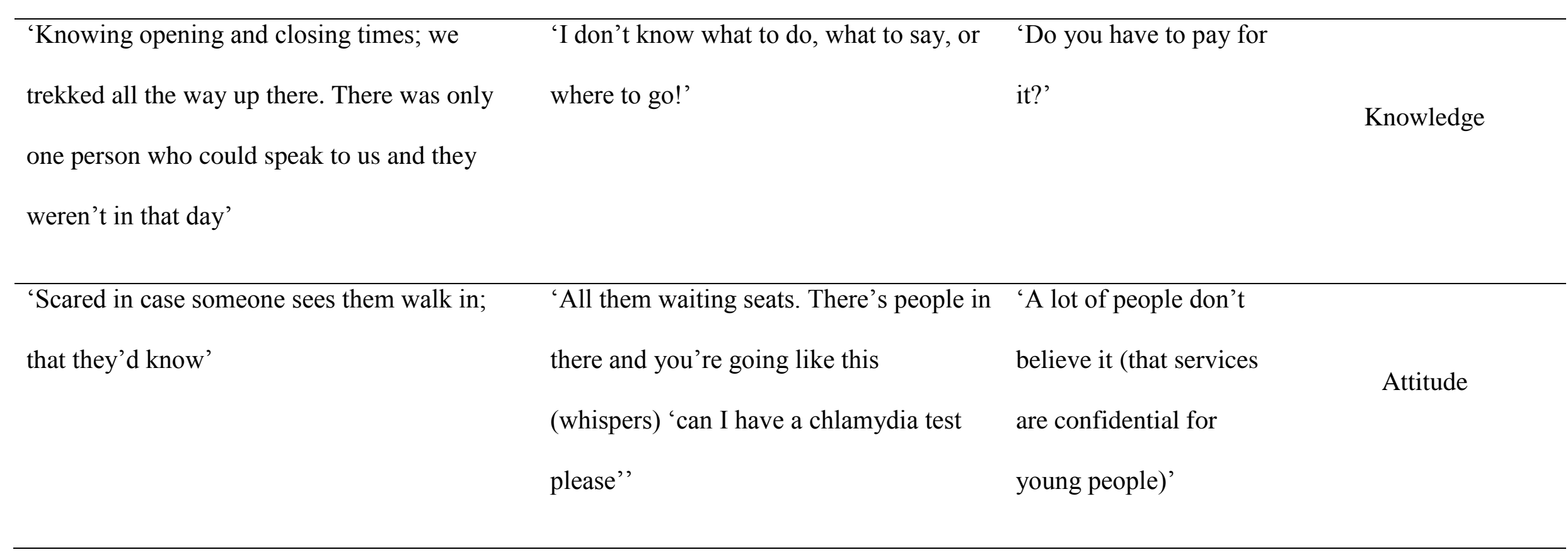




\begin{tabular}{ll}
\hline 'It's the unknown. It's scary. Even thinking 'Embarrassment makes it hard' & 'Not everyone has the \\
about the building and then going in, and this & confidence to say that'
\end{tabular}

is going to happen' confidence to say that'

Perceived Behavioral

Control 
Table III Selected cells from the matrix of change objectives

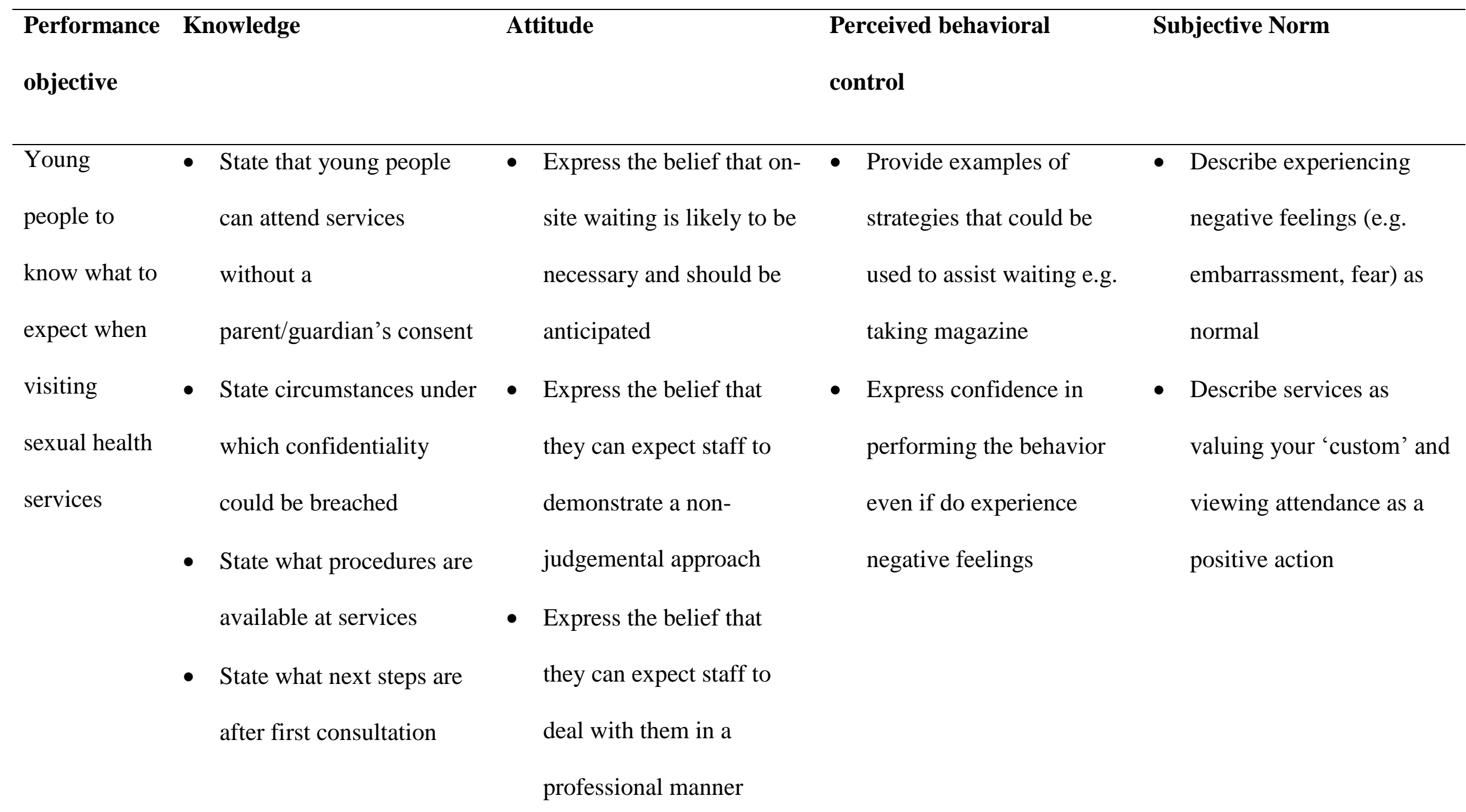


Figure 1

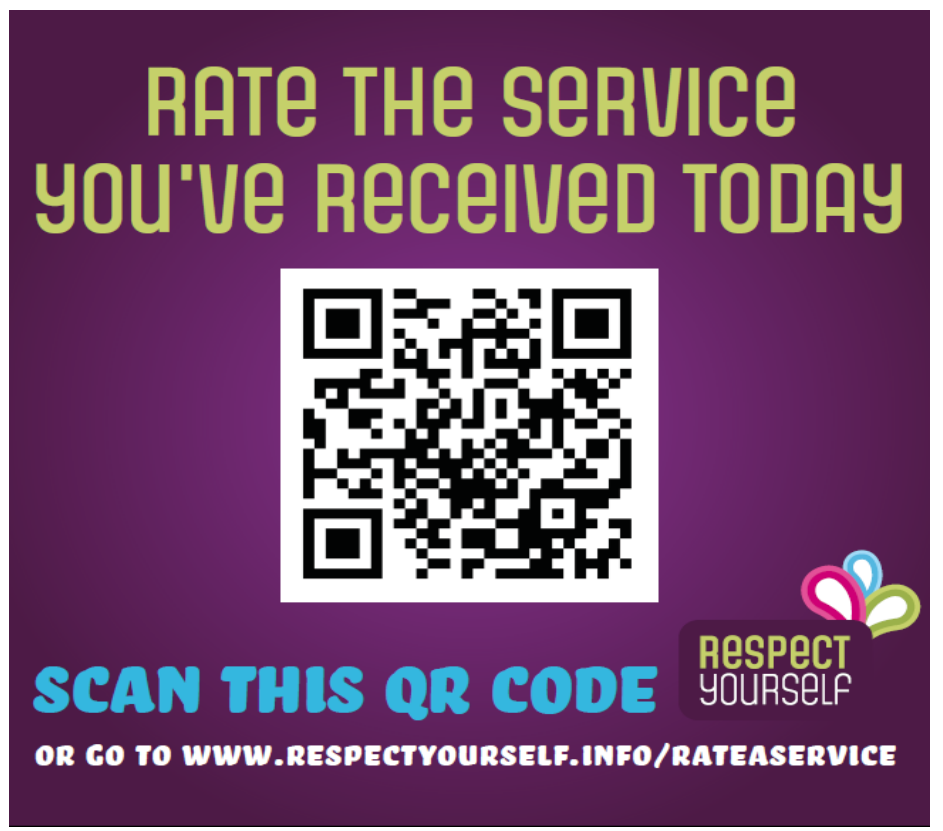

